ORIGINAL ARTICLE

\title{
Referral patterns: an audit into referral practice among doctors in emergency medicine
}

\author{
C Reid, C Moorthy, K Forshaw
}

Emerg Med J 2005;22:355-358. doi: 10.1136/emj.2003.008409

See end of article for authors' affiliations

....................

Correspondence to:

C Reid, The Lister Hospital,

Stevenage, SGI 4AB, UK;

cilla.reid@nhs.net

Accepted

2 November 2003
Objectives: To develop a standard for safe patient referral from emergency medicine (EM) staff to hospital inpatient specialities; to audit adherence to that standard, and from this audit, to identify potential risk areas in this aspect of patient care; to make recommendations for reducing such risks; and to implement those recommendations.

Method: A standard was introduced and practice was compared to that standard using a telephone questionnaire.

Results: Many problems arising at referral were identified. From these, recommendations were made for improvements. At the base hospital, those recommendations were implemented. These potential piffalls are highlighted, together with strategies for improving safe handover of patient care. The discussion includes a review of the literature on safe handovers, which underpins both the importance of this subject and our findings and recommendations.

Conclusions: Referral is an important skill for many doctors, particularly those in EM. It requires teaching and practice. The corollary to this is that education in this arena is also essential for those receiving referrals, to ensure smooth communication and safe systems of handover for patients.
$\mathrm{H}$ andover of patients from doctor to doctor or from one team to another has been identified as a high risk area. Appropriate communication is essential to ensure the safe ongoing care of patients. ${ }^{1-4}$ For doctors working in emergency medicine (EM) this communication is usually in the form of referrals to medical staff working for inpatient specialities. One of the skills integral to efficient working in EM is the art of referral. In this study, we explored the factors influencing EM doctors' referring habits.

A literature search revealed much work on aspects of emergency admissions. Relevant features from these papers are explored in the discussion. However, no formal guidelines were identified on the subject of referrals. As a basis for this audit, we took as our the standard that:

"The decision to refer to a particular specialty should be based on clinical evaluation by the emergency medicine clinicians, and current local practices".

Discussion within our department suggested that other factors, such as the approachability and helpfulness of the receiving specialist, were important. In an attempt to determine what additional factors influence referrals, an audit was carried out questioning EM junior doctors (senior house officers (SHOs), specialist registrars (SpRs), and staff grades (SGs)) about their referral experiences.

\section{METHODS}

A questionnaire was developed (table 1). This was piloted on 30 junior doctors in a 2 week period in December 2001. A further 42 doctors were contacted in a 2 week period in May 2002. Two researchers, (CM and KF) filled in the questionnaires, in person or by telephone. The timing was such that the doctors interviewed could be expected to have had several months of EM experience.

Subject selection was by either telephoning or attending departments, and speaking to those doctors on duty at that time.

\section{Findings}

The average age of the doctors was 27 years; $44 \%$ of the subjects had been qualified $<2$ years and a further $18 \%$ $<3$ years, with the remainder being distributed between 4 and 14 years; $71 \%$ of the subjects questioned were SHOs, $9 \%$ were staff grades, $7 \%$ were SpRs, $7 \%$ were locum SHOs, $6 \%$ were others ( $2 \%$ clinical assistants, $2 \%$ research fellows, and $2 \%$ lecturers); $52 \%$ of the subjects had come to EM directly from pre-registration house officer (PRHO) posts, a further $34 \%$ had had one or two previous SHO posts, and the remaining $14 \%$ had more experience.

\section{Difficulties}

The question "do you have any difficulties with referrals?" was answered affirmatively by $56 \%$. Interestingly, however, further enquiry through the questionnaire elicited problems for every doctor interviewed.

\section{Influential factors}

In the study, $34(47 \%)$ felt the person to whom they had to refer affected their decision, and they often checked the rota before deciding whom to call; 28 (39\%) found their own knowledge of the subject a problem; 21 (29\%) were influenced by a lack of clear protocols for referrals; 18 $(25 \%)$ found their confidence in the receiving doctor important; $11(15 \%)$ were adversely affected by time constraints; $5(7 \%)$ thought that the specialty involved was important; and 4 (5\%) were concerned about communication difficulties.

In addition, many observed that specialty doctors appeared to assume EM doctors were "inferior"; seven doctors referred to "bouncing" patients ( that is, attempts by inpatient teams to steer the patient to another team, for example, renal/ urology); and nine doctors felt pressured by seniors to refer patients.

Abbreviations: $E D$, emergency department; $E M$, emergency medicine; $\mathrm{PRHO}$, pre-registration house officer; $\mathrm{SG}$, staff grade; $\mathrm{SHO}$, senior house officer; SpR, specialist registrar 


\section{Difficult specialities}

There were multiple comments referring to those particular specialities to which respondents found it difficult to refer patients. The three main specialities identified were: (a) orthopaedics $(22 \%),(b)$ surgery $(14 \%)$, and $(c)$ medicine $(20 \%)$. This should be set against the proportion of such referrals, which at this hospital is 13: 17: 70 in this order. Others included gynaecology (11\%); obstetrics (9\%); plastics (5\%); and psychiatry, ENT, and paediatrics (4\% each).

The subjects picked out clear groups of patients they felt that they referred more than was appropriate. Specific reasons for these potentially inappropriate referrals were identified: medicine $32 \%$ (fear of chest pain!); plastics $25 \%$ (all hand injuries were seen by plastics in certain hospitals); orthopaedics 13\% (trauma); and paediatrics (lack of experience and knowledge).

Respondents were clear that senior reviews were not necessary for referrals. However, results of investigations were much more important to the receiving specialities: $46 \%$ were sometimes asked to wait for results before a referral would be accepted. For 33\% this was a frequent occurrence, and $66 \%$ of doctors had experience of this causing unnecessary delay of referrals.

Finally, subjects were asked to give their own opinion on how referrals could be made easier. This resulted in some very relevant comments and some more amusing ones.

- SHOs to have more experience before working in EM.

- More acute experience in PRHO posts.

- Everyone to do EM.

- EM referrals to be "non-negotiable".

- No advice over phone, patient must be reviewed.

- Less adversarial/hostile attitude in specialty doctors.

- Specialities to appreciate the pressures on EM doctors.

- Specialities not insisting on waiting for results before accepting a patient.

- Greater trust between EM and receiving doctors - we are clinicians too and are entitled to support from the specialities.

- Feed back to EM SHOs about patients they referred (and not just the problems).

- Fast track systems.

- Clear guidelines on which specialty takes which referrals (for example, are pubic rami fractures the responsibility of orthopaedic or care of the elderly?).

- American system with specialities based in the ED.

- People answering bleeps!

- People actually wanting to do some work!

- More doctors, fewer patients!

\section{Conclusions from the audit}

1. Accident and emergency doctors are usually young and relatively inexperienced. Many have only been in PRHO posts previously.

2. Multiple factors influence referrals other than our ideal ones: namely clinical findings and local practices.

Key problems were:

Personality clash with accepting doctor.

Particular specialities were difficult to refer to. The EM doctors' knowledge of the subject.

3. The majority of EM doctors feel specialities don't appreciate them or the pressure they are experiencing.

\section{Recommendations}

1. The formal teaching of referral to new EM doctors (and perhaps even in medical school).

2. Understanding of local policies by EM doctors and the specialities.

3. Clear guidelines as to the role of EM and the role of the specialities in accepting patients.

4. Education for the specialities on acceptance of referrals.

5. Building relationships between EM and the other hospital teams.

The ideal should be all specialities including EM working as a team to optimise patient care.

\section{Implementation of recommendations at the Lister hospital}

As a result of this audit, several changes were made to junior doctor education. Firstly, the EM junior medical staff was targeted. The SHO induction at the start of each 6 month post, and the individual induction for middle grades, were amended. The topic of referrals had been mentioned previously but was given a more prominent focus. Role play was introduced so that the new doctors practised telephone referrals of sample patients and these sessions were used to explore some of the difficulties described above. The SHOs taking the part of the inpatient team member proved remarkably adept at portraying the difficult SHO or registrar, drawing, it seems, on role models that they had already encountered. The role and responsibilities of referring and referred to doctors were outlined and the importance of accurate documentation stressed.

When new doctors start working in the ED, they are not allowed to refer on their own for the first 2 weeks. This period was already a time of intense support and supervision for new SHOs, used to teach them both theoretical knowledge and some of the many skills required in EM. Referrals are thus taught practically by middle grades and seniors, based on real cases. We identified "magic phrases" such as:

"I would like you to come and see this patient and give me your opinion."

"I believe this patient requires admission under your care."

"The investigations have been carried out, but I don't think they will affect the need for you to come and assess the patient."

"It may be that after you have seen the patient you decide that another specialty should be involved but my assessment is that (following hospital policy) the patient should be under your team."

These on the job training episodes are used to teach the junior doctors the steps in preparation for referrals:

1. Decide exactly what is needed before making the phone call. This avoids ambiguous use of language such as "I just want to run something by you" or I'm not sure if you are the right person for this".

2. Collect the patient's notes and details before making the referrals. Ensure the relevant facts required to make the referral are known, for example, time of last meal for surgeons, visual acuity for ophthalmology.

3. Ensure that the referral is appropriate. In this, knowing hospital policy is crucial. For example, in this hospital, blunt chest trauma is orthopaedic, while penetrating chest trauma is general surgical. Care of the elderly 
starts at 77 years. Confident knowledge of such details can save much argument.

4. Have some appreciation of the degree of urgency and the level of seniority to approach. Hospital policy may dictate which doctor to call for different specialities, but the referring clinician must know when to be prepared to seek more senior opinions, even if this means waking up consultants. This may depend on degree of urgency, immediate availability, or lack of confidence in the response to referral. In this, the EM juniors must know that they will have the full support of their seniors.

Secondly, we tried to broadcast the findings to the specialty teams. To achieve this, in March 2003 the audit was presented at a hospital grand round, which in this district general hospital is attended by representatives of most hospital specialities and by local GPs. This opened out the discussion and provided education on the topic for the inpatient teams. This led to animated debate, but there was an overall demonstration of support for improving referring and acceptance patterns and overcoming the difficulties highlighted. In particular, the physicians in the audience were quite clear that decisions on patient care should be made on clinical grounds, and that no one should be waiting for results of investigations before seeing referrals. The presence of GPs in the audience led to some discussion about their experiences and difficulties in making referrals, which were not dissimilar to those from EM. It was suggested at the grand round that education about accepting or taking referrals should be included in the hospital induction programme for all new doctors. This last recommendation will be enacted in August 2003 and thenceforth at future hospital inductions.

\section{DISCUSSION}

Communication difficulties cannot be allowed to compromise patient care. Telephone referrals can be the source for misunderstanding and difficulties, which may lead exactly to such compromise. In an ideal world, a referral should be a chance to help a patient, to work with the EM team, possibly to see an interesting case, and to learn from the experience. However, hospital staff in both EM and the inpatient teams often work under pressure. In such conditions, receiving a referral can be a negative experience, bringing unwanted work, interrupting other clinical activities, or postponing sleep. This was identified by the Clinical Standards Advisory Group on emergency admissions, ${ }^{5}$ who found that "delays were often due to doctors seeing other patients and may be due to poor organisation of on take teams, with doctors in theatre or outpatient clinics. Under these conditions, tempers can be fraught and teamwork suffers."

Education about how to refer appropriately and how to accept referrals sets clear markers restoring balance and enabling the team working practices for which we strive.

Communication skills have long been identified as crucial for EM SHOs but these have largely focused on the doctor patient relationship. ${ }^{6}$ Such interpersonal skills are also crucial among colleagues.

Difficulties were identified when EM juniors felt inadequately knowledgeable. This issue was raised by Thakore and Morrison $^{7}$ when looking at patient handover from ambulance crews to EM staff. They identified lack of confidence in paediatric handovers. It must be accepted that EM SHOs are lacking in knowledge and experience, often having only recently registered as fully qualified doctors. A system of 24 hour middle grade and senior "shop floor" support might help with this, but at present is not available in many departments. Thus, the inpatient specialities should recognise that their role is often to supply that knowledge and expertise.

The question arose as to whether all SHO referrals should firstly be reviewed by EM seniors. This is not practicable at present. Such practice could be useful for learning, giving the opportunity to discuss a case with the EM senior and to receive instant feedback. However, at some stage EM SHOs must also learn the art of decision making and that of appropriately taking responsibility. If they always rely on seniors to reinforce their judgements this will not happen.

Safe patient management should be the major priority for all healthcare workers. Paul Barach, the editor of Quality in Health Care, has written a $B M J$ editorial $^{8}$ drawing attention to the chronic "unsafeness" of health systems:

\section{"Inadequate handovers, for example, can mean that vital information is lost between different teams. Care will be safer when we learn to work as teams. The knowledge, skills, and attitudes needed for safe practice are cut across professional, clinical, and organisational boundaries. Unless attention is given to the system our patients are at risk from a faulty service".}

The need for clear guidelines for referrals within a hospital was identified by the Clinical Standards Advisory Group on urgent and emergency admissions to hospital: ${ }^{\prime}$

\section{"Assessment by a house officer of need for admission of emergency patients referred through the accident and emergency department has been described as inappropri- ate, since the need for admission has already been assessed by a more senior doctor in that department".}

They recommended that handover arrangements should be agreed so that patients might be admitted without repeated examination by junior trainees from other departments. They also referred to one subject that was identified in our survey, the lack of trust in the judgement of EM staff by inpatient teams:

\section{"The practice of not trusting the emergency department is widespread and causes distress which has no benefit to either the hospital or the patient".}

This topic was also taken up by Dearden, ${ }^{10}$ who found that the decision to admit was the responsibility of the EM doctors in only $6 \%$ of hospitals. She concluded that detaining medical and surgical patients in the ED for assessment by the ward doctor has no benefit to either the hospital or the patient, and that EM doctors should be entrusted with admitting rights.

\section{CONCLUSION}

This audit identified problems around the topic of patient referrals from EDs. A standard for making referrals was developed. Recommendations for improvement were made and enacted in the base hospital carrying out the audit. Changes in practice were made at that hospital within the ED and education carried out for the rest of the hospital. This gained recognition of the problems and widespread support for practice improvements.

Finally the tongue in cheek comment "more doctors, fewer patients" actually proposes a real solution to reducing pressures on both admitting and EM doctors, improving relationships and team working, and thus the patients' experience of the system and their safe management. 


\section{Authors' affiliations}

C Reid, C Moorthy, K Forshaw, The Lister Hospital, Stevenage, UK

Competing interests: none declared

From an original idea by Dr D Wayne, SHO in Medicine, Oxford

Referral patterns: An audit into referral practice among doctors in emergency departments (ED).

\section{REFERENCES}

Royal College of Physicians. Guidelines on effective handover. RCP handbook. London: RCP Publications Unit, 2001.

2 Royal College of Surgeons of England. Good surgical practice. London: RCS, 2002.
3 General Medical Council. Good medical practice. London: Standards and Ethics Committee, GMC, 1998.

4 Bulstrode C. Continuity of care--sacred cow or vital necessity? BMJ 1995:310:1144-5.

5 Dillner L. Emergency delays need urgent attention. News, BMJ 1995; 310:283.

6 Lloyd G, Skarratts D, Robinson N, et al. Communication skills training for emergency department senior house officers-a qualitative study. Emerg Med J 2000;17:246-50.

7 Thakore S, Morrison W. A survey of the perceived quality of patient handover by ambulance staff in the resuscitation room. Emerg Med 2001; 18:293-6.

8 Barach P, Moss F. Delivering safe health care Editorial. BMJ 2001;323:585-6.

9 Rosen M. Emergency delays. BMJ 16 September 1995;311:754

10 Dearden CH. Emergency delays. BMJ 1995;310:1199.

\section{Register now!}

10th European Forum on Quality Improvement in Health Care 13-15 April 2005, ExCel Conference Centre, London For further information on how to register please go to: http://www.quality.bmipg.com 